\title{
MEDIA ANALISIS DAN SIMULASI GERAK MENGGELINDING DI BIDANG DATAR BERBASIS MATLAB
}

\author{
Nurullaeli \\ Teknik Informatika, Universitas Indraprasta PGRI \\ Jl. Raya Tengah No. 80, Kel. Gedong, Kec. Pasar Rebo, Jakarta Timur, DKI Jakarta \\ leli.biofisika@gmail.com
}

\begin{abstract}
ABSTRAK
Materi gerak menggelinding sebenarnya sudah dipelajari mahasiswa pada jenjang Sekolah Menengah Atas (SMA) jurusan IPA, tetapi masih banyak mahasiswa yang kurang paham mengenai gerak tersebut. Salah satu upaya strategis yang dapat dilakukan, yaitu dengan membuat inovasi media pembelajaran yang menarik dan mudah dimengerti mahasiswa. Tujuan penelitian ini adalah untuk membuat media analisis dan simulasi gerak menggelinding dengan slip dan tanpa slip di bidang datar. Algoritma perhitungan pada gerak menggelinding dituliskan dalam bahasa pemrograman Matlab dan ditampilkan dalam bentuk Grapichal User Interface (GUI). Analisis menggunakan media ini relatif cepat dan memiliki tingkat akurasi yang tinggi. Pada media ini juga disertai simulasi gerak menggelinding dalam bentuk video. Media ini dapat menjadi inovasi media pembelajaran yang dapat digunakan untuk memahami konsep gerak menggelinding di bidang datar.
\end{abstract}

Kata Kunci: gerak menggelinding, GUI, Matlab.

\begin{abstract}
Rolling motion material has actually been studied by college students at the high school level (SMA) majoring in science, but there are still many college students who do not understand the motion. One of the strategic efforts that can be done is by making learning media innovation that is interesting and easy for college students to understand. The purpose of this research is to make media analysis and simulation of rolling motion with slipping and without slipping on a flat surface. The calculation algorithm for rolling motion is written in the Matlab programming language and displayed in the form of a Graphical User Interface (GUI). Analysis using this medium is relatively fast and has a high level of accuracy. This media is also accompanied by a rolling motion simulation in the form of video. This media can be an innovative learning media that can be used to understand the concept of rolling motion on a flat surface.
\end{abstract}

Key Word: rolling motion, GUI, Matlab.

\section{PENDAHULUAN}

Mekanika merupakan salah satu pokok bahasan dalam mata kuliah fisika dasar yang mempelajari gerak benda. "Gerak merupakan perpindahan posisi atau kedudukan suatu titik atau benda terhadap titik acuan tertentu" (Suddin \& Nasrullah, 2017). Salah satu gerak yang sering terjadi di sekitar kita adalah gerak menggelinding. Gerak tersebut merupakan gabungan antara dua gerak, yaitu gerak translasi dan gerak rotasi. Kedua gerak tersebut dilihat berdasarkan bentuk lintasannya. "Gerak translasi dapat didefinisikan sebagai gerak pergeseran suatu benda dengan bentuk dan lintasan yang sama di setiap titiknya. Jadi sebuah benda dapat dikatakan melakukan gerak translasi (pergeseran) apabila setiap titik pada benda itu menempuh lintasan yang bentuk dan panjangnya sama. Sedangkan gerak rotasi dapat didefinisikan sebagai gerak suatu benda dengan bentuk dan lintasan membentuk sudut gerak (rotatinal angel)" (Suddin \& Nasrullah, 2017).

Materi gerak menggelinding sebenarnya sudah dipelajari mahasiswa pada jenjang Sekolah Menengah Atas (SMA) jurusan IPA, tetapi masih banyak mahasiswa yang kurang paham mengenai gerak tersebut dikarenakan pada saat mahasiswa mengenyam pendidikan di tingkat SMA mengalami kesulitan belajar fisika ataupun kurangnya ketertarikan terhadap fisika. Hal ini sesuai dengan hasil penelitian Samudra et al. pada tahun 2014. "Berdasarkan analisis data diperoleh bahwa permasalahan-permasalahan yang dihadapi siswa SMA di Singaraja dalam belajar fisika ada dua yaitu sulitnya memahami pelajaran fisika dan tidak sukanya siswa terhadap pelajaran fisika. Kesulitan siswa dalam mempelajari fisika disebabkan oleh dua hal yaitu materi fisika yang padat, menghapal, dan menghitung, serta pembelajaran fisika di 
kelas yang tidak kontekstual. Tidak sukanya siswa terhadap pelajaran fisika disebabkan karena pada pembelajaran fisika di kelas guru tidak memperhatikan siswa" (Samudra et al., 2014).

"Konsep fisika dasar yang dipahami oleh mahasiswa diidentifikasi dalam tiga kategori yaitu: paham konsep, tidak paham konsep, dan salah konsep. Salah konsep yang dialami mahasiswa pada fisika dasar dapat mengganggu pikirannya dan mengalami kesulitan belajar" (Gustina et al., 2020). Tidak paham konsep ataupun salah konsep pada mahasiswa harus mendapatkan perhatian khusus agar ke depannya tidak mempengaruhi keberhasilan proses belajar mengajar pada mata kuliah lanjutan. Pemahaman konsep yang baik secara tidak langsung akan meningkatkan kualitas pendidikan sehingga mahasiswa setelah lulus mempunyai bekal yang cukup untuk terjun ke dunia kerja. "Peningkatan kualitas pendidikan dilaksanakan diantaranya dalam bentuk pengembangan metode penyampaian materi pembelajaran, pengembangan kurikulum, serta pengembangan berbagai jenis media pembelajaran" (Anesia et al., 2018). Salah satu upaya strategis yang dapat dilakukan, yaitu dengan membuat inovasi media pembelajaran yang menarik dan mudah dimengerti mahasiswa. "Media pembelajaran memiliki peran yang sangat penting dalam mencapai tujuan dari pembelajaran. Hal ini disebabkan media merupakan alat yang digunakan untuk menyampaikan isi dari pembelajaran" (Gunawan, 2014).

"Komputer adalah perangkat yang dapat dimanfaatkan untuk memecahkan berbagai masalah atau general purpose device. Program dalam komputer diistilahkan sebagai software yang memiliki tiga komponen utama yaitu input, proses, dan output" (Didi et al., 2016). Matlab merupakan salah satu software yang dapat digunakan dalam membuat media pembelajaran pada materi gerak menggelinding. "Semua operasi matematika dalam Matlab adalah operasi matriks. Matlab dapat menunjukkan hasil perhitungan dalam bentuk grafik dan dapat dirancang sesuai keinginan kita menggunakan GUI yang kita buat sendiri" (Hutagalung, 2018). "GUI telah menjadi cara penting dan telah diterima dalam berinteraksi dengan perangkat lunak saat ini.
GUI memungkinkan pengguna dapat lebih mudah dan lebih nyaman dalam menjalankan sebuah aplikasi" (Muhtadi et al., 2019). Pembuatan GUI pada Matlab dapat dilakukan dengan dua cara, yaitu menulis seluruh sintak pada editor atau menggunakan fasilitas GUIDE yang telah tersedia. Pembuatan GUI menggunakan fasilitas GUIDE menawarkan kemudahan pembuatan desain kepada pemrogram. Pemrogram tidak harus menulis semua sintak program dalam mendesain GUI. Pemrogram hanya perlu menulis beberapa sintak tambahan seperti perhitungan, memasukkan gambar, memasukkan video, membuat grafik, dan tombol proses lainnya.

"Penggunaan simulasi fisika yang interaktif terbukti sangat bermanfaat digunakan dalam pembelajaran sebab mampu memvisualisasikan gambaran-gambaran fenomena fisika di dalam kelas" (Swandi et al., 2021). Simulasi fenomena fisika yang interaktif dapat dikemas dalam bentuk video. "Video dalam pembelajaran fisika telah banyak dikembangkan pada materi-materi fisika, yang seluruhnya telah valid untuk digunakan sebagai media pembelajaran" (Hafizah, 2020). Pada penelitian ini, peneliti membuat media analisis dan simulasi gerak menggeliding dengan slip dan tanpa slip di bidang datar menggunakan fasilitas GUIDE di Matlab. Pada GUI yang dibuat dilengkapi dengan simulasi gerak berupa video agar mahasiswa dapat mempunyai gambaran yang lebih jelas mengenai gerak tersebut tanpa harus melakukan percobaan.

\section{METODE PENELITIAN}

Metode penelitian yang dilakukan terdiri dari beberapa langkah, yaitu studi pustaka, analisis rumus gerak menggelinding dengan slip dan tanpa slip di bidang datar, pembuatan video simulasi gerak menggelinding, pembuatan GUI, dan analisis sistem fisis.

Studi pustaka dilakukan untuk lebih memahami konsep gerak menggelinding dengan slip dan tanpa slip. Selain itu, kepustakaan yang diperoleh dapat membantu peneliti mengetahui perkembangan dari bidang yang diteliti dan membantu peneliti dalam proses analisis hasil pemrograman.

Setelah kepustakaan yang diperoleh cukup, peneliti melakukan analisis rumus gerak 
menggelinding dengan slip dan tanpa slip pada bidang datar. Gerak menggelinding pada penelitian ini terdiri dari empat macam, yaitu gerak menggelinding dengan slip di bidang datar dengan kondisi $\mathrm{v}>\omega \mathrm{R}$, gerak menggelinding dengan slip di bidang datar dengan kondisi $\mathrm{v}<\omega \mathrm{R}$, gerak menggelinding tanpa slip di bidang datar ketika benda ditarik gaya pada porosnya, dan gerak menggelinding tanpa slip di bidang datar ketika benda ditarik gaya pada sisi luarnya. Di mana $\mathrm{v}$ adalah kecepatan translasi, $\omega$ adalah kecepatan sudut, dan $\mathrm{R}$ adalah jari-jari benda. Ilustrasi keempat gerak tersebut dapat dilihat pada gambar 1.

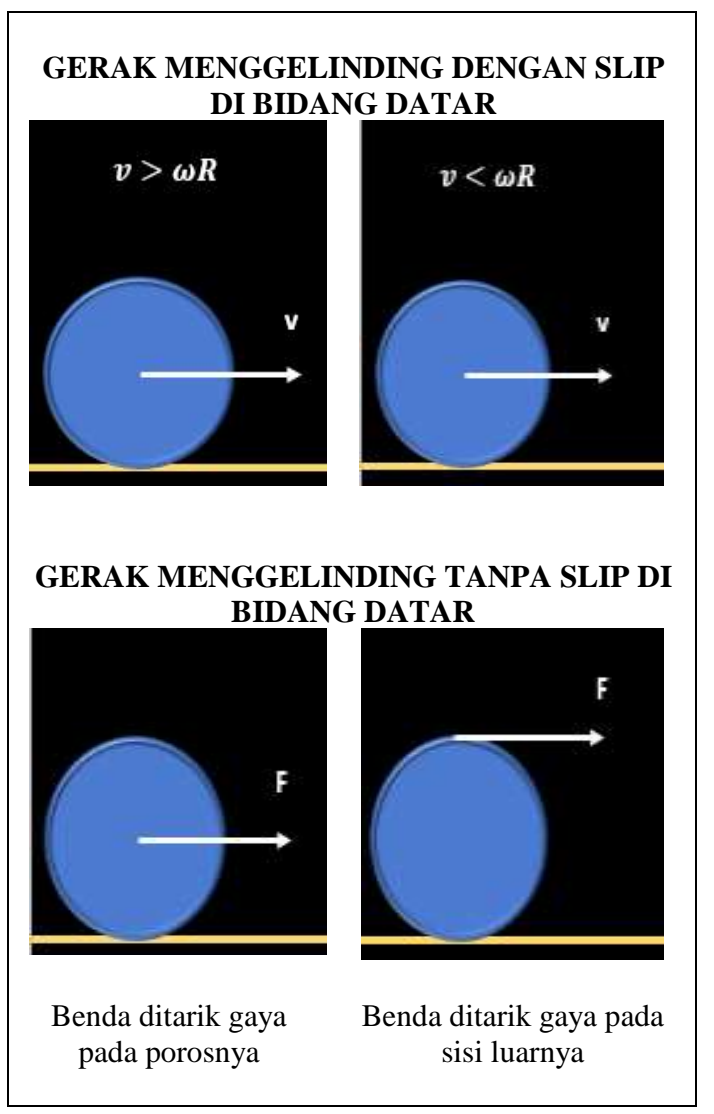

Gambar 1. Ilustrasi Gerak Menggelinding

Pada analisis rumus gerak menggelinding, peneliti mengambarkan ilustrasi gaya yang terjadi di setiap gerak, kemudian gerak tersebut dianalisis menggunakan rumus yang berlaku pada gerak translasi dan rotasi sehingga didapatkan hasil akhir berupa rumus yang digunakan dalam pembuatan GUI.

Langkah selanjutnya, peneliti membuat video simulasi gerak menggelinding. Video dibuat menggunakan PowerPoint 2019 dan disimpan dalam format MP4. Video yang dibuat kemudian diubah ke dalam format AVI menggunakan bantuan software camtasia. Perubahan format video dilakukan karena software yang digunakan peneliti dalam pembuatan GUI, yaitu Matlab R2013a tidak mendukung video dalam format MP4.

Hasil analisis rumus gerak menggelinding dan video yang telah didapatkan, dibutuhkan peneliti dalam pembuatan GUI. Hasil analisis rumus gerak menggelinding digunakan untuk menyusun algoritma perhitungan dan video digunakan untuk simulasi gerak menggelinding yang akan ditampilkan di GUI. Semua algoritma ditulis dalam bahasa pemrograman Matlab yang dikemas dalam bentuk GUI dengan memanfaatkan fasilitas GUIDE yang telah disediakan oleh Matlab.

Langkah terakhir, peneliti melakukan analisis gerak mengelinding menggunakan GUI yang telah dibuat, kemudian peneliti melakukan analisis sistem fisis dari hasil perhitungan GUI.

\section{HASIL DAN PEMBAHASAN}

Algoritma perhitungan merupakan hal penting yang harus ditentukan terlebih dahulu sebelum pembuatan GUI. Algoritma perhitungan ini disusun berdasarkan hasil analisis rumus gerak menggelinding di bidang datar menggunakan rumus yang berlaku pada gerak translasi dan rotasi. Hasil analisis rumus gerak menggelinding di bidang datar dengan slip dapat dilihat pada tabel 1 .

Tabel 1. Hasil Analisis Rumus Gerak Menggelinding di Bidang Datar dengan Slip

\begin{tabular}{lcc}
\hline \multicolumn{1}{c}{ Rumus } & Gerak Menggelinding dengan Slip \\
& $\mathbf{v}>\boldsymbol{\omega R}$ & $\mathbf{v}<\boldsymbol{\omega R}$ \\
\hline $\begin{array}{l}\text { Percepatan } \\
\text { Linear }\end{array}$ & $\mathrm{a}=-\mu_{\mathrm{k}} \mathrm{g}$ & $\mathrm{a}=\mu_{\mathrm{k}} \mathrm{g}$ \\
$\begin{array}{l}\text { Percepatan } \\
\text { Sudut }\end{array}$ & $\propto=\frac{\mu_{\mathrm{k}} \mathrm{g}}{\mathrm{kR}}$ & $\propto=\frac{-\mu_{\mathrm{k}} \mathrm{g}}{\mathrm{kR}}$ \\
$\begin{array}{l}\text { Gaya } \\
\text { Gesek }\end{array}$ & $\mathrm{f}_{\mathrm{k}}=\mathrm{kmR} \propto$ & $\mathrm{f}_{\mathrm{k}}=-\mathrm{kmR} \propto$ \\
Kinetis & & \\
$\begin{array}{l}\text { Momen } \\
\text { Gaya }\end{array}$ & $\Sigma \tau=\mathrm{f}_{\mathrm{k}} \mathrm{R}$ & $\Sigma \tau=-\mathrm{f}_{\mathrm{k}} \mathrm{R}$ \\
Waktu & $\mathrm{v}_{0} \mathrm{k}$ & $t_{1}=\frac{\omega_{0} \mathrm{R} \mathrm{k}}{(\mathrm{k}+1) \mu_{\mathrm{k}} \mathrm{g}}$ \\
$\begin{array}{l}\text { Mencapai } \\
\text { Kondisi }\end{array}$ & $(\mathrm{k}+1) \mu_{\mathrm{k}} \mathrm{g}$ & \\
Tidak Slip & & \\
\hline
\end{tabular}

Sedangkan hasil analisis rumus gerak menggelinding di bidang datar tanpa slip dapat dilihat pada tabel 2 . 
Tabel 2. Hasil Analisis Rumus Gerak Menggelinding di Bidang Datar Tanpa Slip

\begin{tabular}{lcc}
\hline Rumus & $\begin{array}{c}\text { Gerak Menggelinding Tanpa Slip } \\
\text { Benda Ditarik } \\
\text { Gaya pada } \\
\text { Porosnya }\end{array}$ & $\begin{array}{c}\text { Genda Ditarik } \\
\text { Gaya pada Sisi } \\
\text { Luarnya }\end{array}$ \\
\hline $\begin{array}{l}\text { Percepatan } \\
\text { Linear }\end{array}$ & $\mathrm{a}=\frac{F}{(1+k) m}$ & $\mathrm{a}=\frac{2 F}{(1+k) m}$ \\
$\begin{array}{l}\text { Percepatan } \\
\text { Sudut }\end{array}$ & $\propto=\frac{a}{\mathrm{R}}$ & $\propto=\frac{a}{\mathrm{R}}$ \\
$\begin{array}{l}\text { Gaya } \\
\text { Gesek }\end{array}$ & $\mathrm{f}_{s}=\mathrm{kma}$ & $\mathrm{f}_{s}=(\mathrm{kma})-\mathrm{F}$ \\
$\begin{array}{l}\text { Statis } \\
\text { Momen } \\
\text { Gaya }\end{array}$ & $\Sigma \tau=\mathrm{f}_{s} \mathrm{R}$ & $\Sigma \tau=\mathrm{kmaR}$ \\
\hline
\end{tabular}

Pada penelitian ini algoritma perhitungan ditulis dalam bahasa pemrograman Matlab yang dikemas dalam GUI dengan memanfaatkan fasilitas GUIDE. GUI ini digunakan sebagai media analisis dan simulasi gerak menggelinding di bidang datar. GUI yang dibuat peneliti terdiri dari lima jendela, yaitu satu jendela halaman awal dan empat jendela untuk analisis serta simulasi gerak menggelinding. Setiap jendela dilengkapi dengan menu editor (Analisis dan Simulasi) untuk memilih jendela selanjutnya yang akan dibuka sehingga dapat memudahkan pengguna dalam menggunakan media tersebut.

Pada jendela halaman awal, pengguna dapat memilih jenis analisis dan simulasi gerak menggelinding pada menu Analisis dan Simulasi yang terletak di sebelah kiri atas jendela tersebut serta pengguna dapat keluar dari jendela dengan menekan tanda silang (X) yang terletak di sebelah kanan atas jendela tersebut. Tampilan jendela halaman awal dapat dilihat pada gambar 2 .

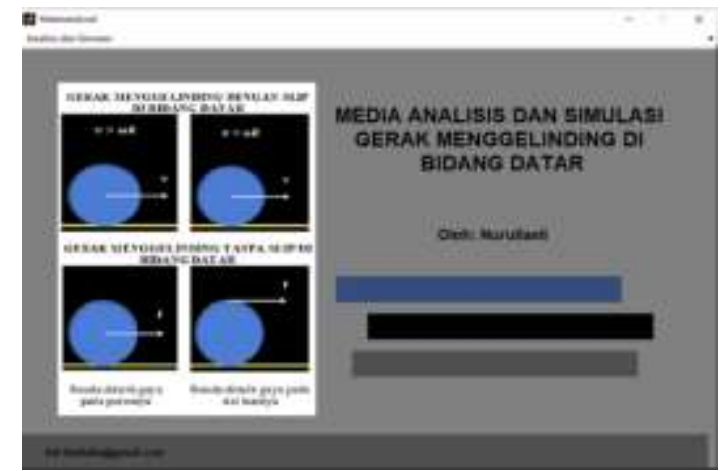

Gambar 2. Tampilan Jendela Halaman Awal

Jendela kedua, yaitu jendela yang digunakan sebagai media analisis dan simulasi gerak menggelinding dengan slip di bidang datar dengan kondisi $v>\omega R$. Pada kondisi ini, gerak translasi lebih dominan dari pada gerak rotasi. Untuk proses analisis, pengguna harus memasukkan terlebih dahulu variabel masukan berupa massa benda (m), jari-jari benda $(\mathrm{R})$, konstanta inersia $(\mathrm{k})$, koefisien gesek kinetis $\left(\mu_{\mathrm{k}}\right)$, dan kecepatan linear awal $\left(\mathrm{v}_{0}\right)$. Langkah selanjutnya, pengguna dapat memilih perhitungan yang akan dilakukan. Pilihan perhitungan dalam jendela ini, yaitu perhitungan percepatan linear (a), percepatan sudut $(\alpha)$, gaya gesek kinetis $\left(f_{k}\right)$, momen gaya $(\Sigma \tau)$, dan waktu mencapai kondisi tidak slip ( $\mathrm{t}_{1}$ ) yang dikemas dalam button group. Setelah memilih jenis perhitungan, pengguna dapat menekan tombol PROSES dan hasil perhitungan dapat dilihat di bagian hasil. Untuk melakukan analisis dengan nilai masukan berbeda, pengguna dapat menekan tombol RESET yang berfungsi mengembalikan nilai variabel ke nilai semula (kosong) kemudian melakukan langkahlangkah seperti sebelumnya. Pada jendela ini, pengguna dapat melihat simulasi gerak menggelinding dengan slip di bidang datar dengan kondisi $\mathrm{v}>\omega \mathrm{R}$ dalam bentuk video. Cara melihat simulasi, yaitu dengan menekan tombol PUTAR ANIMASI. Untuk keluar dari jendela, pengguna dapat menekan tombol KELUAR atau menekan tanda silang (X) yang terletak di sebelah kanan atas jendela tersebut. Tampilan jendela analisis dan simulasi gerak menggelinding dengan slip di bidang datar dengan kondisi $\mathrm{v}>\omega \mathrm{R}$ dapat dilihat pada gambar 3 dan contoh hasil analisis gerak menggelinding dengan slip di bidang datar dengan kondisi $\mathrm{v}>\omega \mathrm{R}$ dapat dilihat pada tabel 3. Pada tabel 3 terlihat bahwa hasil perhitungan media analisis dan simulasi yang dibuat peneliti sama dengan hasil perhitungan secara manual. Nilai percepatan linear yang didapatkan bernilai negatif karena untuk menyeimbangkan antara gerak translasi dan rotasi sehingga benda mencapai kondisi tidak slip. 


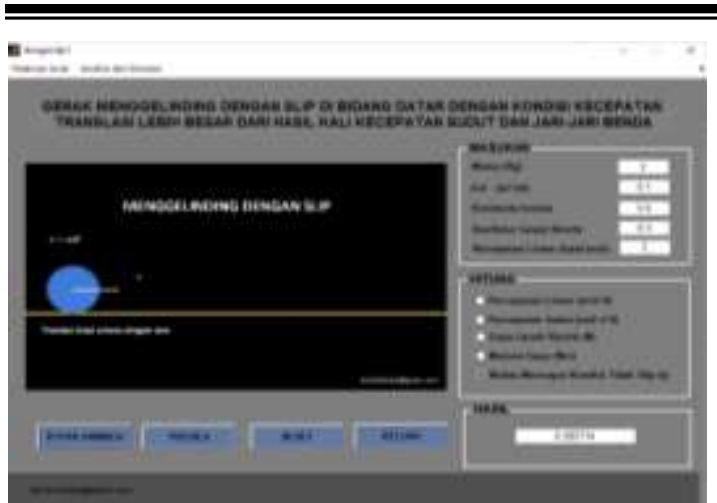

Gambar 3. Tampilan Jendela Analisis dan Simulasi Gerak Menggelinding dengan Slip di Bidang Datar dengan Kondisi $\mathbf{v}>\omega \mathrm{R}$

Tabel 3. Hasil Analisis Gerak Menggelinding dengan Slip di Bidang Datar dengan Kondisi $v>\omega R$ dengan $m=2 \mathrm{~kg}, R=0.1 \mathrm{~m}, \mathrm{k}=2 / 5, \mu_{\mathrm{k}}=0,3$,

\begin{tabular}{|c|c|c|}
\hline $\begin{array}{c}\text { Jenis } \\
\text { Perhitungan }\end{array}$ & $\begin{array}{c}\text { Hasil } \\
\text { Perhitungan } \\
\text { Media Analisis } \\
\text { dan Simulasi }\end{array}$ & $\begin{array}{c}\text { Hasil } \\
\text { Perhitungan } \\
\text { Secara } \\
\text { Manual } \\
\end{array}$ \\
\hline $\mathrm{a}\left(\mathrm{m} / \mathrm{s}^{2}\right)$ & -3 & -3 \\
\hline$\alpha\left(\mathrm{rad} / \mathrm{s}^{2}\right)$ & 75 & 75 \\
\hline $\mathrm{f}_{\mathrm{k}}(\mathrm{N})$ & 6 & 6 \\
\hline$\sum \tau(\mathrm{Nm})$ & 0.6 & 0.6 \\
\hline $\mathrm{t}_{1}(\mathrm{~s})$ & 0.285714 & 0.285714 \\
\hline
\end{tabular}

Jendela ketiga, yaitu jendela yang digunakan sebagai analisis dan simulasi gerak menggelinding dengan slip di bidang datar dengan kondisi $\mathrm{v}<\omega \mathrm{R}$. Pada kondisi ini, gerak rotasi lebih dominan dari pada gerak translasi. Langkah-langkah untuk proses analisis dan melihat simulasi gerak pada jendela ketiga sama dengan langkah-langkah pada jendela kedua, hanya saja pada jendela ketiga masukan kecepatan linear awal $\left(\mathrm{v}_{0}\right)$ diganti dengan kecepatan sudut awal $\left(\omega_{0}\right)$. Tampilan jendela analisis dan simulasi gerak menggelinding dengan slip di bidang datar dengan kondisi $\mathrm{v}<\omega \mathrm{R}$ dapat dilihat pada gambar 4 dan contoh hasil analisis gerak menggelinding dengan slip di bidang datar dengan kondisi $\mathrm{v}<\omega \mathrm{R}$ dapat dilihat pada tabel 4. Pada tabel 4 terlihat bahwa hasil perhitungan media analisis dan simulasi yang dibuat peneliti sama dengan hasil perhitungan secara manual. Nilai percepatan sudut yang didapatkan bernilai negatif karena untuk menyeimbangkan antara gerak translasi dan rotasi sehingga benda mencapai kondisi tidak slip.

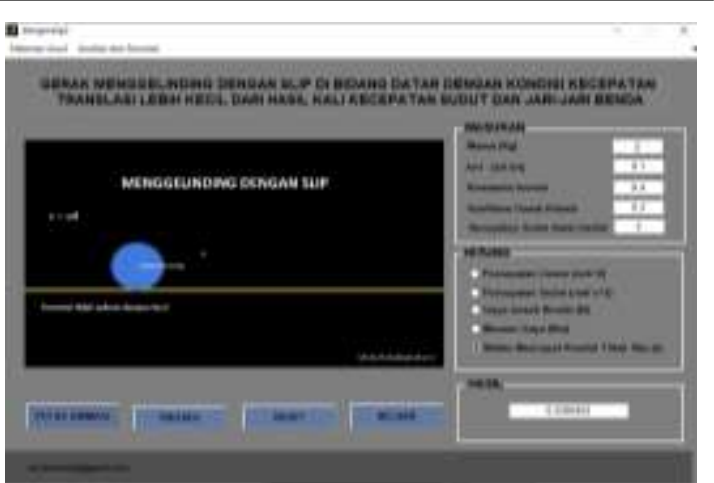

Gambar 4. Tampilan Jendela Analisis dan Simulasi Gerak Menggelinding dengan Slip di Bidang Datar dengan Kondisi $\mathbf{v}<\omega \mathrm{R}$

Tabel 4. Hasil Analisis Gerak Menggelinding dengan Slip di Bidang Datar dengan Kondisi $\mathrm{v}<\omega \mathrm{R}$ dengan $\mathrm{m}=2 \mathrm{~kg}, \mathrm{R}=0.1 \mathrm{~m}, \mathrm{k}=2 / 5, \mu_{\mathrm{k}}=0,3$,

\begin{tabular}{|c|c|c|}
\hline $\begin{array}{c}\text { Jenis } \\
\text { Perhitungan }\end{array}$ & $\begin{array}{c}\text { Hasil } \\
\text { Perhitungan } \\
\text { Media Analisis } \\
\text { dan Simulasi }\end{array}$ & $\begin{array}{c}\text { Hasil } \\
\text { Perhitungan } \\
\text { Secara } \\
\text { Manual } \\
\end{array}$ \\
\hline $\mathrm{a}\left(\mathrm{m} / \mathrm{s}^{2}\right)$ & 3 & 3 \\
\hline$\alpha\left(\mathrm{rad} / \mathrm{s}^{2}\right)$ & -75 & -75 \\
\hline $\mathrm{f}_{\mathrm{k}}(\mathrm{N})$ & 6 & 6 \\
\hline$\sum \tau(\mathrm{Nm})$ & -0.6 & -0.6 \\
\hline$t_{1}(s)$ & 0.0380952 & 0.0380952 \\
\hline
\end{tabular}

Pada jendela keempat dan kelima, pengguna dapat melakukan analisis dan melihat simulasi gerak menggelinding tanpa slip di bidang datar. Jendela keempat dikhususkan ketika kondisi benda ditarik gaya pada porosnya dan jendela kelima dikhususkan ketika kondisi benda ditarik gaya pada sisi luarnya. Untuk proses analisis, pengguna harus memasukkan terlebih dahulu variabel masukan berupa gaya $(\mathrm{F})$, massa benda (m), jari-jari benda (R), dan, konstanta inersia (k). Langkah selanjutnya, pengguna dapat memilih perhitungan yang akan dilakukan. Pilihan perhitungan dalam jendela ini, yaitu perhitungan percepatan linear (a), percepatan sudut $(\alpha)$, gaya gesek statis $\left(\mathrm{f}_{\mathrm{s}}\right)$, dan momen gaya $(\Sigma \tau)$ yang dikemas dalam button group. Setelah memilih jenis perhitungan, pengguna dapat menekan tombol PROSES dan hasil perhitungan langsung dapat dilihat pada bagian hasil. Untuk melihat simulasi, pengguna dapat menekan tombol PUTAR ANIMASI. Pada jendela keempat dan kelima juga dilengkapi dengan tombol RESET dan KELUAR yang fungsinya sama dengan tombol RESET dan KELUAR pada jendela kedua dan ketiga. Untuk keluar dari jendela keempat dan kelima, pengguna juga dapat menekan tanda silang (X) yang terletak di sebelah kanan atas jendela tersebut. 
Tampilan jendela analisis dan simulasi gerak menggelinding tanpa slip di bidang datar ketika benda ditarik gaya pada porosnya dapat dilihat pada gambar 5 dan contoh hasil analisis gerak menggelinding tanpa slip di bidang datar ketika benda ditarik gaya pada porosnya dapat dilihat pada tabel 5. Pada tabel 5 terlihat bahwa hasil perhitungan media analisis dan simulasi yang dibuat peneliti sama dengan hasil perhitungan secara manual.

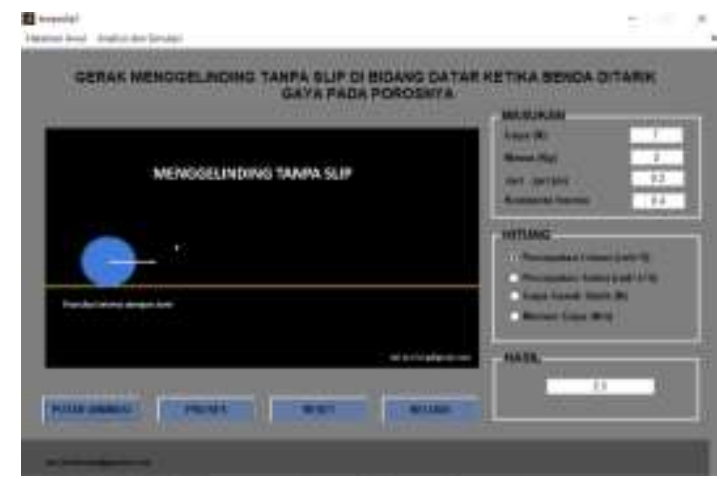

Gambar 5. Tampilan Jendela Analisis dan Simulasi Gerak Menggelinding Tanpa Slip di Bidang Datar Ketika Benda Ditarik Gaya pada Porosnya

Tabel 5. Hasil Analisis Gerak Menggelinding Tanpa Slip di Bidang Datar Ketika Benda Ditarik Gaya pada Porosnya dengan $\mathrm{F}=7 \mathrm{~N}, \mathrm{~m}=2 \mathrm{~kg}, \mathrm{R}=0.2 \mathrm{~m}$,

\begin{tabular}{ccc} 
Jenis & dan $\mathbf{k}=\mathbf{2} / \mathbf{5}$ & Hasil \\
Perhitungan & $\begin{array}{c}\text { Herhitungan } \\
\text { Media Analisis } \\
\text { dan Simulasi }\end{array}$ & $\begin{array}{c}\text { Perhitungan } \\
\text { Secara } \\
\text { Manual }\end{array}$ \\
\hline $\mathrm{a}\left(\mathrm{m} / \mathrm{s}^{2}\right)$ & 2.5 & 2.5 \\
$\alpha\left(\mathrm{rad} / \mathrm{s}^{2}\right)$ & 12.5 & 12.5 \\
$\mathrm{f}_{s}(\mathrm{~N})$ & 2 & 2 \\
$\sum \tau(\mathrm{Nm})$ & 0.4 & 0.4 \\
\hline
\end{tabular}

Tampilan jendela analisis dan simulasi gerak menggelinding tanpa slip di bidang datar ketika benda ditarik gaya pada sisi luarnya dapat dilihat pada gambar 6 dan contoh hasil analisis gerak menggelinding tanpa slip di bidang datar ketika benda ditarik gaya pada sisi luarnya dapat dilihat pada tabel 6. Pada tabel 6 terlihat bahwa hasil perhitungan media analisis dan simulasi yang dibuat peneliti sama dengan hasil perhitungan secara manual. Untuk nilai gaya gesek statis yang didapatkan bernilai negatif karena sebelumnya dalam analisis rumus peneliti memisalkan arah gaya gesek statis berlawanan arah dengan arah gaya tarik. Seharusnya arah gaya gesek statis searah dengan arah gaya untuk menyeimbangkan gerak rotasi yang ditimbulkan gaya karena gaya yang diletakkan pada sisi luar benda mempunyai peran besar menyumbang kecepatan rotasi benda.

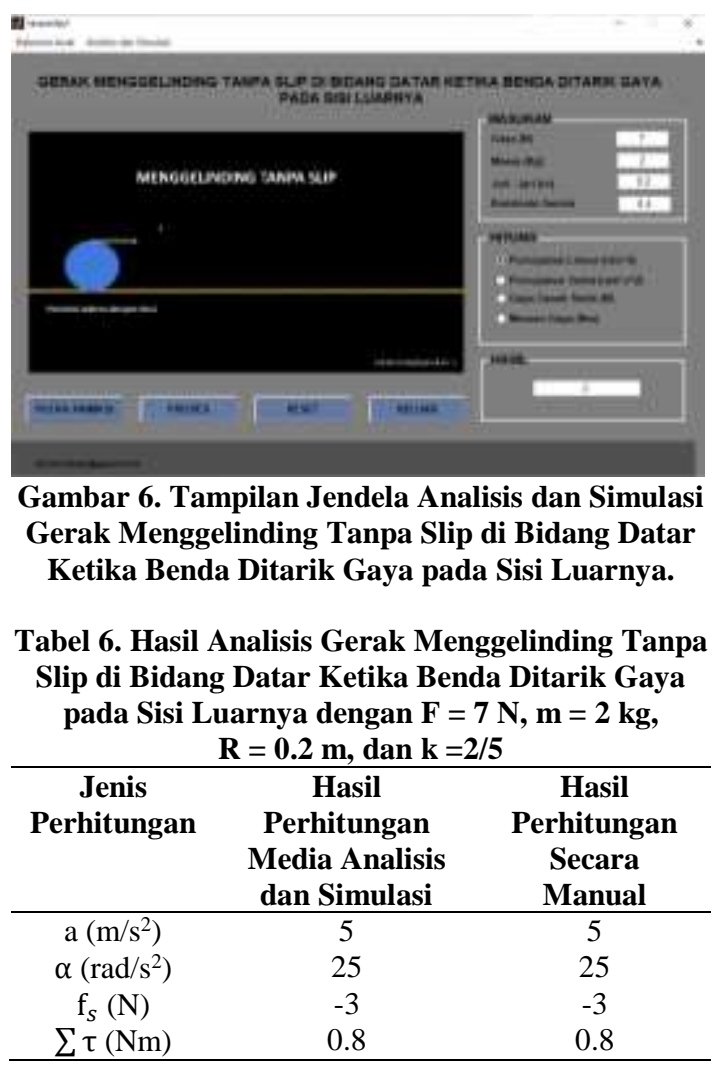

\section{SIMPULAN DAN SARAN}

Hasil perhitungan media analisis dan simulasi gerak menggelinding di bidang datar berbasis Matlab yang dibuat peneliti sama dengan hasil perhitungan secara manual. Analisis menggunakan media ini relatif cepat dan memiliki tingkat akurasi yang tinggi. Pada media ini juga disertai simulasi gerak menggelinding dalam bentuk video untuk mempermudah mahasiswa memahami konsep gerak tersebut. Oleh karena itu, media ini dapat menjadi inovasi media pembelajaran yang dapat digunakan untuk memahami konsep gerak menggelinding di bidang datar.

Adapun saran untuk penelitian selanjutnya, perlu dibuat GUI mengenai gerak menggelinding yang menyajikan analisis dan simulasi lebih lengkap.

\section{DAFTAR PUSTAKA}

Anesia, R., Anggoro, B. ., \& Gunawan, I. (2018). Pengembangan Media Komik Berbasis Android Pada Pokok Bahasan Gerak Lurus. Indonesian Journal of Science and Mathematics Education, l(1), 
https://ejournal.radenintan.ac.id/index.p $\mathrm{hp} / \mathrm{IJSME} / \mathrm{index}$

Didi, M., Marindani, E. D., \& Elbani, A. (2016). Rancang Bangun Pengendalian Robot Lengan 4 DOF dengan GUI ( Graphical User Interface ) Berbasis Arduino Uno. Jurnal Teknik Elektro Universitas Tanjungpura, 1(1), 1-11. https://jurnal.untan.ac.id/index.php/jteu ntan/article/view/14580

Gunawan, I. (2014). Pengembangan Aplikasi Mobile Learning Fisika Sebagai Media Pembelajaran Pendukung. Jurnal Ilmiah Pendidikan Fisika Al-Biruni, 3(1), 2026.https://doi.org/10.24042/jpifalbiruni. v3i1.62

Gustina, G., Kamaluddin, K., Ali, M., \& Syamsuriwal, S. (2020). Analisis Pemahaman Konsep Fisika pada Mahasiswa Program Studi Pendidikan Fisika FKIP UNTAD. JPFT (Jurnal Pendidikan Fisika Tadulako Online), 8(1).http://jurnal.untad.ac.id/jurnal/inde x.php/EPFT/article/view/15831

Hafizah, S. (2020). Penggunaan Dan Pengembangan Video Dalam Pembelajaran Fisika. Jurnal Pendidikan Fisika, 8(2), 225-240. https://doi.org/10.24127/jpf.v8i2.2656

Hutagalung, S. N. (2018). Menggunakan Aplikasi Matlab Metode Simulink Siti Nurhabibah Hutagalung Jurusan Teknik Informatika , STMIK Budi Darma. Journal of Science and Social Research, 1(1), 30-35. http://jurnal.goretanpena.com/index.php /JSSR/article/view/96

Muhtadi, M. M., Friyadi, M. D., \& Rahmani, A. (2019). Analisis GUI Testing pada Aplikasi E-Commerce menggunakan Katalon. Prosiding Industrial Research Workshop and National Seminar, 10(1), 1387-1393.

https://jurnal.polban.ac.id/proceeding/ar ticle/view/1443\%0Apolban.ac.id

Samudra, G. B., Suastra, I. W., \& Suma, K. (2014). Permasalahan-Permasalahan Yang Dihadapi Siswa SMA Di Kota Singaraja Dalam Mempelajari Fisika. Jurnal Pendidikan Dan Pembelajaran IPA Indonesia, 4(1). https://ejournalpasca.undiksha.ac.id/index.php/jurnal_i pa/article/view/1093

Suddin, D., \& Nasrullah, B. (2017). Rancang Bangun Robot Manipulator Yang
Bergerak Secara Translasi Dan Rotasi. Prosiding Seminar Hasil Penelitian Dan Pengabdian Kepada Masyarakat (SNP2M), 151-156. http://snp2m.poliupg.ac.id/2017/

Swandi, A., Rahmadhanningsih, S., Viridi, S., Nurhayati, N., Putri, R. A., \& Suryadi, A. (2021). Simulasi Gerak Translasi Dan Gerak Melingkar Menggunakan Vba Macro Excel Melalui Project Based Learning (PBL). JPF (Jurnal Pendidikan Fisika) Universitas Islam Negeri Alauddin Makassar, 9(1), 33. https://doi.org/10.24252/jpf.v9i1.20519 